\title{
Matematički modeli u kriminologiji
}

\author{
Maja Bukovec, Igor Pažanin
}

\section{Sažetak}

Uloga matematičkog modeliranja u društvenim je znanostima važna te su do danas predstavljeni mnogi matematički modeli koji opisuju razne društvene fenomene. Cilj ovog rada prezentirati je nekoliko matematičkih modela koji se koriste u proučavanju kriminala, a opisani su običnim diferencijalnim jednadžbama.

Ključni pojmovi: matematičko modeliranje, kriminologija, predator-plijen modeli, epidemiološki modeli

\section{Uvod}

Kako je derivacija mjera promjene, diferencijalnim jednadžbama se najjednostavnije izražavaju i modeliraju mnogi prirodni i društveni zakoni te razni procesi u različitim područjima znanosti i tehnike (v. npr. [4]). U ovom radu bavit ćemo se matematičkim modelima kojima je cilj pridonijeti razumijevanju određenih teorijskih mehanizama u kriminologiji. Rad je podijeljen na dva dijela. U prvom dijelu predstavit ćemo klasu modela baziranih na Lotka-Volterra teoriji dvije konkurentske populacije (tzv. predator-plijen modeli). U drugom dijelu opisat ćemo klasu tzv. epidemioloških modela gdje se protok među podpopulacijama, tj. regrutacija u podpopulaciju kriminalaca, može dogoditi samo nekom vrstom „zaraze”. Rad je utemeljen na preglednom članku [3] i dio je diplomskog rada [5].

Iako sama primjena matematičkog modeliranja u kriminologiji nema dugu tradiciju, razvoj kvantitativnog i formalnog pristupa proučavanju 
kriminala zapravo je započeo prije mnogo godina. Adolphe Quételet 1 , otac moderne statistike, predstavio je ideju „društvene fizike” još u 19. stoljeću i može se smatrati utemeljiteljem uporabe statistike i sociologije u proučavanju kriminala. Sociolog Gabriel Tard $\AA^{2}$ je također pridonio razvoju modeliranja u kriminologiji te, u novije vrijeme, Gary Becker ${ }^{3}$ čiji su radovi polazna točka u proučavanju kriminala, posebice iz perspektive ekonomije.

Uloga modeliranja $\mathrm{u}$ društvenim znanostima općenito, a posebice $\mathrm{u}$ proučavanju kriminala, dolazi u nekoliko oblika koji odražavaju različite svrhe. Prvo, kvantitativna analiza i modeliranje zahtijevaju točno određen okvir i jasno definirane pojmove radi preciznog pristupa problemu i prikladnog korištenja statističkih podataka. Nadalje, druga svrha korištenja matematike je u izgradnji modela $u$ idealnim uvjetima i pod točno odredenim pretpostavkama. Cilj tih modela je dodatno razumijevanje odabranih teorijskih mehanizama te testiranje ograničenja koja nam daju osnovne pretpostavke modela. Svrha ovako kompleksne strukture modeliranja kriminala nije u reprezentaciji cjelokupne stvarnosti, niti u davanju točnih predviđanja. Međutim, ovakav pristup može nam pomoći u boljem razumijevanju činjenica koje karakteriziraju modeliranje u kriminologiji te pridonijeti novom pogledu na cjelokupnu sliku teorijskog modela. Uz pomoć matematičkih modela u poziciji smo istražiti razne učinke npr. težine kazne, vremenskog trajanja zatvorske kazne, različitih strategija zastrašivanja te tako naći najučinkovitiji način raspodjele resursa u svrhu smanjenja i sprječavanja zločina.

Jedna od najvažnijih primjena modeliranja u ovom području učinci su raznih pravila, kontrola i ograničenja u borbi protiv kriminala. Razvoj cijele teorije oslanja se na analizu podataka, u početku pri izgradnji modela, ili pak na kraju pri njegovoj evaluaciji. Međutim, podaci nam često zadaju znantne poteškoće. Ponajprije, u mnogim zemljama i gradovima podaci su iznimno teško dostupni iz određenih političkih razloga, politike represivnog aparata odnosno iz nekih drugih povjerljivih razloga. No, čak i tamo gdje su podaci dostupni, problematična može biti usporedba rezultata ili modela među zemljama zbog razlika u zakonima i definicijama raznih vrsta zločina. U novije vrijeme može se pronaći dosta literature koja se bavi ovakvim pitanjima.

Sam spoj matematike i kriminologije zasnovan je na činjenici da je matematičarima od koristi baza podataka kako bi testirali svoje metode i modele, a kriminolozi posjeduju podatke koje treba analizirati. Nave-

\footnotetext{
${ }^{1}$ A. Quételet, The Propensity to Crime, 1831., Sur l'homme et le développement de ses facultés, ou Essai de physique sociale, Paris, 1835.

${ }^{2} \mathrm{G}$. Tarde, La criminalité comparée, 1886.

${ }^{3}$ G. S. Becker, Crime and Punishment: An Economic Approach, J. Political Econ. 76 (1968), $169--217$.
} 
dimo neka važna pitanja vezana uz analizu podataka u krimonologiji na koja je potrebno odgovoriti:

- Većina je podataka koje treba analizirati jako velikih dimenzija. Smanjenje dimenzionalnosti podataka i odredivanje relevantnih parametara i varijabli nužan je korak pri korištenju tih podataka.

- Skupovi podataka nerijetko sadrže prostorne i vremenske pogreške. Primjer prostorne pogreške je zapis policijske postaje kao mjesta zločina umjesto stvarne lokacije gdje se zločin dogodio. Primjer vremenske pogreške može biti trovanje nekim metalom poput žive ili olova, gdje simptomi postanu uočljivi tek dugo vremena nakon samog zločina. Ovakvi slučajevi i pogreške moraju se ukloniti kako bi se mogli izvući valjani zaključci iz danih podataka.

- Veliki problem u nesavršenosti podataka može se pojaviti kod nekih tipova zločina poput proizvodnje i preprodaje droge gdje nemamo podatke o glavnim počiniteljima te organizatorima kriminala.

Pri modeliranju u kriminologiji mnoštvo je parametara koje treba uzeti u obzir:

(a) Opservacije - broj počinjenih kaznenih djela (određenog tipa) kao funkcija vremena i položaja.

(b) Varijable stanja koje želimo promatrati, primjerice:

- dob i raspodjela dohotka

- mobilnost

- društvena segregacija, segregacija stanovanja, škole, grada itd.

- obrasci kriminala, organizacija kriminala.

(c) Kontrolne funkcije, primjerice:

- policija i policijske strategije

- društvena kontrola

- provedba zakona (težina kazne)

- socijalna politika, socijalna pomoć, politika školstva itd.

Zaključno, valja naglasiti da, iako matematički modeli nisu dovoljni za kvantitativna predviđanja (primjerice predviđanje broja provala koje će se dogoditi sljedećeg mjeseca u određenom dijelu grada), mogu nam dati sugestiju kvalitativnog ponašanja promatranog društvenog sustava i simulirati kakve posljedice može imati promjena kontrolnih funkcija. U 
skladu s tim, matematički modeli mogu itekako biti iskoristivi u izradi strategija za suprotstavljanje kriminalu te u pronalasku najučinkovitijeg načina raspodjele resursa namijenjenih borbi protiv zločina.

\section{Kriminologija i dinamika populacije: pre- dator-plijen modeli}

Ova klasa modela uglavnom je bazirana na predator-plijen modelima, tj. na Lotka-Volterra teoriji dvije konkurentske populacije. Osnovne jednadžbe takvog modela glase:

$$
\left\{\begin{array}{l}
\dot{C}=\alpha C-b C G, \\
\dot{G}=-\alpha G+\beta C G,
\end{array}\right.
$$

gdje $C$ i $G$ predstavljaju populaciju plijena, odnosno predatora, a $\alpha, \beta$ i $b$ su pozitivni parametri. Od sada pa nadalje, sa označavamo derivaciju po vremenu $t$. Društveni problem kontrole kriminalnih aktivnosti poprima sličan oblik ako interpretiramo $C$ kao populaciju koja čini kaznena djela (tj. kriminalci), a $G$ kao populaciju koja nastoji suzbiti kriminal provođenjem zakona ( $\mathrm{tj}$. čuvari). Ovdje koristimo pretpostavku da bi se uz odsutnost kontrole i prevencije kriminala, broj kriminalaca povećavao. Također, trebali bi uzeti u obzir i utjecaj „vanjskog” svijeta na opisane dvije populacije, pa sustav (1) poprima oblik:

$$
\left\{\begin{array}{l}
\dot{C}=\alpha C-b C G+A, \\
\dot{G}=-\alpha G+\beta C G+B,
\end{array}\right.
$$

gdje $A$ i $B$ predstavljaju spomenuti „,vanjski” utjecaj.

\subsection{Model trokuta}

Sada ćemo predstaviti složeniji model koji promatra tri podpopulacije: populacija kriminalaca $C$, populacija čuvara $G$ i populacija meta $T$ (v. 6]). Ovdje su mete $T$ plijen za kriminalce $C$, čuvari $G$ su predatori za $C$, a može se promatrati i da su čuvari $G$ predatori i za $T$ obzirom da oni snose trošak sustava provođenja zakona.

Izvod modela baziran je na sljedećim pretpostavkama:

- Kriminalno djelo počinjeno je svaki put kada član populacije kriminalaca $C$ susretne člana populacije meta $T$. 
- U svakom počinjenom kriminalnom djelu možemo razlikovati dvije faze. Prva, kada kriminalac „traži” odnosno uhodi žrtvu (metu), nakon koje slijedi druga faza, kada kriminalac izvršava samo kriminalno djelo. Uvažavajući takvo ponašanje, možemo uvesti funkciju (v. [2]):

$$
A_{f}(t)=\frac{k T(t)}{E+T(t)} C(t),
$$

gdje su konstante $k, E \geq 0$.

- Proces neutralizacije kriminalaca od strane čuvara dan je sljedećom funkcijom:

$$
S_{f}(t)=\frac{H C(t)}{D+C(t)} G(t),
$$

gdje su $H, D \geq 0$ konstante. Parametar $H$ predstavlja tzv. učinkovitost čuvara.

Uz ove pretpostavke, jednadžbe modela glase:

$$
\left\{\begin{array}{l}
\dot{T}=r(N-T)(K-T)-\frac{k T}{E+T} C-B \frac{G}{T}, \\
\dot{C}=f \frac{k T}{E+T} C-\frac{H C}{D+C} G-F C-J C^{2}, \\
\dot{G}=g \frac{k T}{E+T} C-h \frac{H C}{D+C} G-M G .
\end{array}\right.
$$

Prva jednadžba u sustavu (5) opisuje činjenicu da u odsustvu kriminalaca i čuvara, populacija meta prati logističku dinamiku sa stopom rasta $r>0$ i maksimalnim kapacitetom $N>0$. Parametar $K<N$ optimalna je dostižna populacija tako da $T(t) \rightarrow K$ kada $t \rightarrow \infty$ ako vrijedi $0 \leq$ $T \leq K$ ili $K \leq T<N$. Također, prisutnost kriminalaca otežava rast populacije meta po stopi danoj u (3). S druge strane, prisutnost čuvara predstavlja trošak za populaciju $T$ što je opisano posljednjim članom desne strane prve jednadžbe sustava (5), gdje je konstanta $B>0$.

Druga jednadžba sustava (5) opisuje evoluciju populacije kriminalaca po vremenu $t$. Uzeto je da $C$ raste po stopi opisanoj u (3) sa konstantom proporcionalnosti $f>0$. S druge strane, $C$ se smanjuje pri djelovanju populacije $G$ po stopi opisanoj u (4) te, kao posljedicu međusobnog „nadmetanja” ove dvije populacije, imamo zadnja dva člana desne strane druge jednadžbe u sustavu (5).

Naposljetku, zadnja jednadžba sustava (5) govori nam da je rast od $G$ proporcionalan $(g>0)$ počinjenim kriminalnim djelima. Zatim, $G$ se smanjuje zbog posljedica susreta kriminalaca i čuvara po stopi $h>0$. 
Posljednje podrazumijeva smanjenje od $G$ radi korupcije ili nekih drugih mehanizama. Također, posljednji član zadnje jednadžbe odnosi se na prirodno smanjenje populacije $G$, gdje je konstanta $M>0$.

Treba naglasiti da, kako bi model bio relevantan, potrebne su pouzdane procjene prethodno spomenutih parametara na temelju prikupljenih podataka. Kao što smo već spomenuli, dobivanje takvih procjena predstavlja veliki izazov u polju matematičke kriminologije.

\subsection{Model proizvodnje i prodaje droga}

Ovaj model opisuje interakciju između ilegalnog prodavača droga (dilera) i proizvođača droga (v. [1]). Važno je napomenuti da, što je veći broj dilera, to je veći oportunitetni trošak potencijalnog proizvođača da ne proizvodi. Isto tako, što je veći broj proizvođača, to je lakše pribaviti drogu za prodaju.

- Pretpostavimo da imamo dvije različite i konstantne populacije. Prva populacija sastoji se od dilera i potencijalnih dilera čiji je ukupan broj jednak $\bar{g}$. Broj dilera u trenutku $t$ jednak je $b(t)$ $(0 \leq b(t) \leq \bar{g})$, a broj potencijalnih dilera je $\bar{g}-b(t)(0 \leq \bar{g}-b(t) \leq$ $\bar{g})$. Druga populacija se sastoji od proizvođača i potencijalnih proizvođača kojih ukupno ima $\bar{f}>0$. Broj proizvođača je $n(t)$, a broj potencijalnih proizvođača $\bar{f}-n(t)$.

- Pretpostavljamo da se populacija dilera smanjuje po stopi $h_{1}>0$ proporcionalno ukupnom broju trenutnih dilera te da se populacija proizvođača smanjuje po stopi $h_{2}>0$ proporcionalno ukupnom broju trenutnih proizvođača.

- Populacija dilera povećava se po stopi $k_{1}>0$ proporcionalno broju potencijalnih dilera i trenutnih proizvođača te populacija proizvođača raste po stopi $k_{2}>0$ proporcionalno broju potencijalnih proizvođača i trenutnih dilera.

- Pretpostavimo da proizvođači neće postati dileri i obrnuto.

Uz gornje pretpostavke, dolazimo do sljedećeg modela:

$$
\left\{\begin{array}{l}
\dot{b}=-h_{1} b+k_{1}(\bar{g}-b) n, \\
\dot{n}=-h_{2} n+k_{2}(\bar{f}-n) b .
\end{array}\right.
$$




\section{Kriminologija i dinamika populacije: epi- demiološki modeli}

U ovoj klasi modela, regrutacija u podpopulaciju kriminalaca trebala bi se dogoditi nekom vrstom "zaraze" ostatka populacije od strane kriminalaca.

\subsection{Matematički model četiri podpopulacije}

Predstavit ćemo model s tri podpopulacije, koji ćemo kasnije proširiti i na četvrtu podpopulaciju (v. [7]). Cilj je modela sintetizirati ključne faktore koji utječu na veličinu pojedine populacije kako bismo bolje razumjeli dinamiku aktivnosti u kriminologiji. Model formiramo na osnovu sljedećih pretpostavki:

- Imamo 3 podpopulacije. Prva je podpopulacija pojedinaca koji nisu podložni „zarazi”, tj. neće se upuštati u bilo kakve kriminalne radnje i tu podpopulaciju označimo s $N$. Sljedeću podpopulaciju čine pojedinici koji su podložni „zarazi”, tj. postoji vjerojatnost da počine neko kriminalno djelo. U ovu grupaciju spadaju i oni koji vrlo rijetko počine neko manje kazneno djelo. Označimo sa $S$ ovu podpulaciju. Posljednja podpopulacija se sastoji od pravih kriminalaca i nju označavamo s $C$.

- Pretpostavljamo da se „zaraza” širi društvenom interakcijom, tj. društvenim kontaktom među pojedincima.

- Protok između podpopulacija $N$ i $S$ prvenstveno se odvija zbog demografskog kretanja te društvenih i ekonomskih uvjeta.

- Fluktuacija iz $S$ u $C$ događa se dijelom zbog učinka društvenih i ekonomskih uvjeta, a dijelom zbog društvene interakcije, odnosno kada podložni pojedinci „pokleknu” pod utjecajem kriminalaca iz $C$.

- Konačno, postoji i fluktuacija iz $C$ u $N$. Ona je dijelom uzrokovana općom netolerancijom društva prema kriminalu, a dijelom kao posljedica kazni i drugih oblika „zastrašivanja”.

Prezentirajmo sada formalni matematički model gore opisanih tokova među podpopulacijama. Pretpostavimo da je fluktuacija u podpopulaciju te iz nje proporcionalna njenoj veličini. Tako je protok iz $N$ u $S$ proporcionalan sa $N$, gdje parametar $\theta>0$ predstavlja veličinu protoka. Tok iz $S$ u $N$ modeliramo uz parametar $\mu>0$, a funkcija 
$\tau(N)=A+B N, A, B>0$ opisuje tok između $C$ i $N$ koji je posljedica raznih kazni, metoda zastrašivanja i netolerancije prema kriminalu. Slijedeći gore navedeno, dolazimo do sljedećeg sustava diferencijalnih jednadžbi:

$$
\left\{\begin{array}{l}
\dot{N}=-\theta N+\mu S+\tau(N) C, \\
\dot{S}=\theta N-\mu S-\alpha S-\lambda S C, \\
\dot{C}=\alpha S+\lambda S C-\tau(N) C .
\end{array}\right.
$$

Ovdje $\alpha S$ predstavlja protok iz $S$ u $C$ kao posljedicu društvenih i ekonomskih uvjeta, a $\lambda S C$ protok iz $S$ u $C$ kao posljedicu socijalne interakcije tih dviju podpopulacija.

Naravno, gore opisani model upotpunjujemo uvjetom

$$
N+S+C=1 .
$$

Primjetimo da veće vrijednosti parametara $\alpha$ i $\theta$ povećavaju podpopulaciju $C$. Također, ako veličina toka iz podpopulacije $N$ u $S, \theta$, raste, tada raste i ravnotežno stanje $C^{*}$. Isto vrijedi i za parametre $\alpha$ i $\lambda$. Nadalje, ako parametar $\mu$ raste, tada $C^{*}$ pada. Povećanje učinka društvene netolerancije prema kriminalu smanjuje $C^{*}$.

Proširimo sada model uvođenjem još jedne podpopulacije: podpopulacije zatvorenika $P$. Vrijede sljedeće modifikacije:

- Tok između podpopulacija kriminalaca $C$ i zatvorenika $P$ bi mogao formirati zatvorenu petlju s obzirom na visoku vjerojatnost ponavljanja kaznenih djela bivših zatvorenika.

- S $\varphi_{2}$ označimo konstantu koja ovisi o prosječnom trajanju zatvorske kazne, a sa $\varphi_{1}$ vjerojatnost odlaska u zatvor, tj. tok između $C$ i $P$.

- Vjerojatnost odlaska u zatvor, $\varphi_{1}$, ovisi o tri faktora:

- o vjerojatnosti da kriminalac bude osuđen za počinjeno kazneno djelo

- o prosjeku počinjenih kaznenih djela po pojedincu u određenom vremenu

- o vjerojatnosti odlaska u zatvor ako je pojedinac osuđen.

- Parametar $\pi$ opisuje tok iz podpopulacije $P$ u podpopulacije $C$ i $N$. Sa $(1-\pi)$ označimo vjerojatnost ponavljanja kriminalnih radnji bivših zatvorenika, a s $\pi$ vjerojatnost da bivši zatvorenik neće ponoviti iste pogreške. 
- Uvodimo još jedan parametar, $\gamma$, koji opisuje tok iz $S$ u $N$ kao posljedicu veličine broja osuđenih kriminalaca. Neka je $\delta P, \delta>1$ ukupan broj osuđenih pojedinaca. Tada je $\gamma=\gamma_{0} \delta$, gdje je $\gamma_{0}$ parametar „zastrašivanja”, no radi jednostavnosti zapisa uvodimo samo parametar $\gamma$.

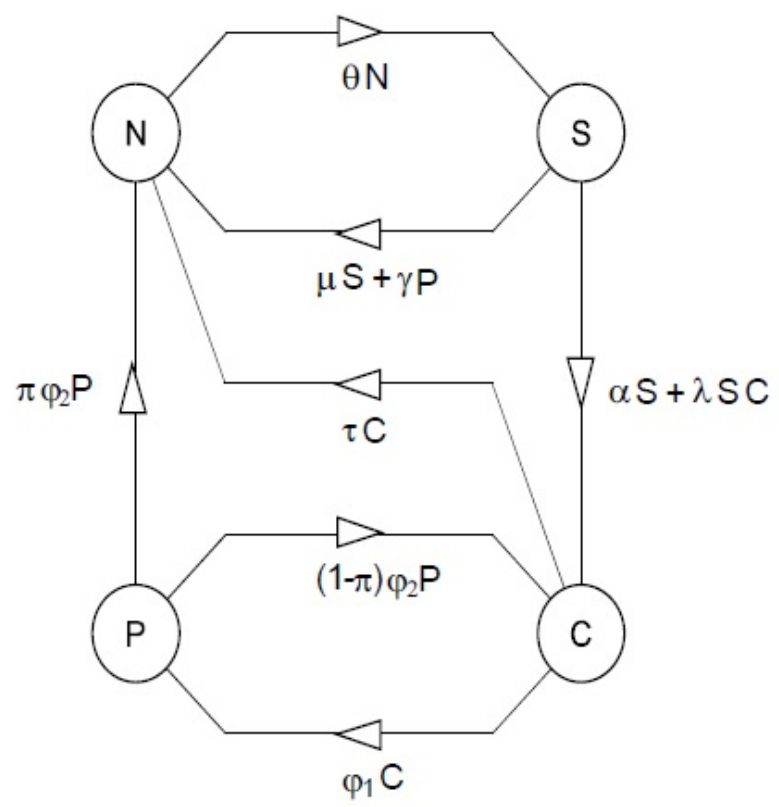

Slika 1: Grafički prikaz proširenja modela (7)

Temeljem gornjih pretpostavki, proširenje modela $(7)$ dano je sustavom:

$$
\left\{\begin{array}{l}
\dot{N}=-\theta N+\mu S+\tau(N) C+\gamma P+\pi \varphi_{2} P \\
\dot{S}=\theta N-\mu S-\alpha S-\lambda S C-\gamma P \\
\dot{C}=\alpha S+\lambda S C-\tau(N) C-\varphi_{1} C+\varphi_{2} P-\pi \varphi_{2} P \\
\dot{P}=\varphi_{1} C-\varphi_{2} P .
\end{array}\right.
$$

Takoder, model upotpunjujemo uvjetom

$$
N+S+C+P=1 .
$$


Grafički prikaz proširenog modela dan je na Slici 1 Cjelokupni model može biti koristan za razumijevanje kako stopa kriminala evoluira tijekom vremena te poslužiti u razmatranju učinka politike u kriminologiji. No, primijetimo da ovaj model ne uključuje podpopulaciju čuvara. Taj problem mogao bi se riješiti kombiniranjem dvaju tipova modela.

\subsection{Modeliranje veze siromaštva i kriminala}

Poznato nam je da su siromaštvo i kriminal dva vrlo velika i povezana problema današnjice. U ovom dijelu intencija nam je predstaviti model koji opisuje dinamiku i povezanost istih (v. 8]).

Promatramo populaciju koja je podijeljenja na 5 podpopulacija:

- P - podpopulacija slabijeg imovinskog statusa (tzv. „siromašni”)

- C - podpopulacija kriminalaca

- J - podpopulacija zatvorenika

- R - podpopulacija „oporavljenih”, odnosno svi bivši zatvorenici te oni koji su bili slabijeg imovinskog stanja (tj. oni koji više nisu u popopulaciji siromašnih)

- N - podpopulacija srednjeg ili višeg imovinskog statusa (tj. nisu siromašni).

Veličina ukupne populacije je konstantna, tj. vrijedi $T=P+C+J+$ $R+N$. Parametri koje ćemo koristiti u konstrukciji modela su:

- $\sigma$ - označava stopu protoka pojedinaca iz $N$ u $P$; ovisi o stopi nezaposlenosti jer je siromaštvo povezano sa (ne)zaposlenosti

- $\gamma$ - opisuje tok iz $P$ u $R$ i odražava socijalnu politiku vlade

- $\rho$ - stopa po kojoj osuđenici odlaze u zatvor

- $\delta$ - stopa po kojoj pojedinci izlaze iz zatvora

- $\mu$ - stopa smrtnosti (pošto je $\mathrm{T}$ konstanta, $\mu$ je ujedno i stopa rađanja).

Nadalje, pretpostavimo da postoji određena vjerojatnost da pojedinac iz $P$ postane kriminalac nakon društvene interakcije s pojedincem iz $C$. Zato s $\beta \frac{P C}{T}$ označimo one pojedince koji će prijeći iz $P$ u $C$. Isto tako, oni iz podpopulacije $R$ također mogu postati kriminalci nakon međusobnog kontakta, ali po manjoj stopi. Zato $\phi \beta \frac{R C}{T}, 0 \leq \phi \leq 1$, označava one iz $R$ koji prijeđu u $C$. Nadalje, pretpostavlja se da pojedinac, nakon 
što izađe iz zatvora, odlazi u podpopulaciju $R$ i ako ponovno dođe $\mathrm{u}$ kontakt s kriminalcima, po stopi $\phi \beta$ postaje jedan od njih. Svi navedeni parametri su nenegativni.

Uz navedene pretpostavke, interakcija između siromaštva i kriminala određena je sustavom kojeg možemo prikazati formalno sljedećim sustavom običnih diferencijalnih jednadžbi:

$$
\left\{\begin{array}{l}
\dot{N}=\mu T-(\sigma+\mu) N \\
\dot{P}=\sigma N-\beta P \frac{C}{T}-(\gamma+\mu) P, \\
\dot{C}=\beta P \frac{C}{T}+\phi \beta R \frac{C}{T}-(\rho+\mu) C, \\
\dot{J}=\rho C-(\delta+\mu) J \\
\dot{R}=\gamma P+\delta J-\phi \beta R \frac{C}{T}-\mu R
\end{array}\right.
$$

uz uvjet

$$
T=N+P+C+J+R .
$$

\section{Literatura}

[1] R. A. Araujo, T. B. S. Moreira, A dynamic model of production and traffic of drugs, Econ. Lett. 82 (2004), 371-376.

[2] A. A. Berryman, The origins and evolution of predator-prey theory, Ecology 73 (1992), 1530-1535.

[3] I. Borsi, M. Primicerio, Mathematical models for social and economic dynamics and for tax evasion: a summary of recent results, Vietnam J. Math. Appl. 12 (2014), 25-48.

[4] J.R. Brannan, W.E. Boyce, Differential Equations: An Introduction to Modern Methods $\&$ Applications, John Wiley \& Sons, San Francisco, 2007.

[5] M. Bukovec, Matematičko modeliranje nekih društvenih fenomena, diplomski rad, PMF-Matematički odsjek, Zagreb, 2018.

[6] J. C. Nuno, M. A. Herrero, M. Primicerio, A triangle model of criminality, Physica A: Stat. Mech. Appl. 387 (2008), 29262936 .

[7] P. Ormerod, C. Mounfield, L. Smith, Non-linear modelling of burglary and violent crime in the UK, Volterra Consulting Ltd, 2001. 
[8] H. Zhao, Z. Feng, C. Castillo-Chavez, The dynamics of poverty and crime, preprint MTBI-02-08M 9 (2002), 311-327.

Maja Bukovec

studentica PMF-Matematičkog odsjeka, Sveučilište u Zagrebu, Bijenička 30, Zagreb

E-mail adresa: maja.bukovec95@gmail.com

Igor Pažanin

PMF-Matematički odsjek, Sveučilište u Zagrebu, Bijenička 30, Zagreb E-mail adresa: pazanin@math.hr 